\title{
Emerging Subspecialties in Neurology: Sports neurology training and certification
}

\section{An overview in 2018}

Joel C. Morgenlander, MD, and Brian Hainline, MD

Neurology ${ }^{\circledR}$ 2018;91:980-982. doi:10.1212/WNL.0000000000006552

Correspondence

Dr. Morgenlander

Joel.morgenlander@

duke.edu

\begin{abstract}
Sports neurology is a relatively new specialty in neurology. Interested trainees may find it difficult to learn about issues in sports neurology both in medical school and residency. This review highlights what the current state is in medical school and residency training and how an interested trainee or neurologist could pursue a career in this area.

Providers with different medical specialty backgrounds can be at the core of a team involved in the neurologic care of athletes of all ages. Education and care centered on the problem of concussion (mild traumatic brain injury [mTBI]) is at the core of sports neurology and has fueled expansion of clinical services. Other important neurologic issues may affect the individual athlete, but expansion of baseline testing and care for concussion has been central to the growth of this specialty. When we critically evaluate the education of most physician trainees pertaining to concussion or mTBI, we see that it is limited. This review details existing medical school and residency education concerning sports neurology, proposes 2 training pathways for the resident interested in a substantial sports neurology practice, and reviews practice opportunities for trained neurologists.
\end{abstract}

The fundamental educational constructs taught in allopathic medical schools come from the Liaison Committee on Medical Education of the American Association of Medical Colleges. ${ }^{1}$ This group defines medical school educational objectives. That said, each medical school determines its own specific curriculum for each subject. The content of each neurology medical student course, therefore, is determined by that medical school and neurology department. It is likely that no material specific to sports neurology is presented in medical schools, and there may not even be education concerning concussion diagnosis and management. The suggested Neurology Clerkship Core Curriculum endorsed by the American Academy of Neurology (AAN) mentions head trauma under "potential emergencies" but does not mention concussion or mTBI. ${ }^{2}$ Most likely the component effects of concussion including headache, cognitive dysfunction, dizziness/vertigo, sleep disorder, neck pain, and depression/anxiety are covered as symptom complexes either alone or as part of other disorders.

Several specialties train physicians who care for patients with various sports-related neurologic disorders. These include neurology, neurosurgery, physical medicine and rehabilitation (PM\&R), and fellowships in sports medicine for those from primary care backgrounds. While all of the component effects of concussion are taught in neurology residency programs, the core educational requirements as listed through the Accreditation Council for Graduate Medical Education Milestones Project for Adult Neurology only list "cognitive effects of traumatic brain injury" under cognitive disorders as the only mention of concussive type injury. ${ }^{3}$ There is no specific mention of sports neurology, sports-related concussion, or other traumatic injuries. The Child Neurology Milestones list "cognitive effects of traumatic brain injury, including 


\section{Glossary}

AAN = American Academy of Neurology; $\mathbf{m T B I}=$ mild traumatic brain injury; PM\&R = physical medicine and rehabilitation.

concussion" with no direct mention of any other aspects of sports neurology. ${ }^{4}$ Neurological Surgery Milestones require patient care and knowledge concerning traumatic brain and spinal cord injury, but this information focuses on catastrophic events such as polytrauma, skull fracture, need for intracranial pressure monitoring, cerebral edema, and spine fracture. ${ }^{5}$ Milestones pertinent to PM\&R specialists list brain and spine trauma but focus more on significant complications of major nervous system injury such as spasticity, autonomic dysfunction, major neurocognitive disability, incontinence, and sensorimotor deficits. ${ }^{6}$ This is not to say that medical residents will not cover common sports neurology issues during residency, but rather that even common problems like sports-related concussion cannot be assumed to be covered by the program, forcing the resident to independently find education in this area.

There are 2 major postresidency pathways for training in sports neurology. First, fellowships in sports neurology are available for graduating neurology residents. These fellowships typically last 1 or 2 years depending on research activities and are increasing in number. They comprise programs in both academic and private practice settings. The AAN organized a section on sports neurology. The section aims to promote the development of education about sports neurology during neurology residency, as well as to assist with the formation of additional sports neurology fellowships. While no board certification exists for trainees in these fellowships, it would be logical to assume that with additional sports neurology fellowships forming, the programs will seek certification from the United Council of Neurologic Subspecialties.

Second, physicians specializing in emergency medicine, family medicine, internal medicine, pediatrics, and $\mathrm{PM} \& \mathrm{R}$ are eligible to pursue a sports medicine fellowship through their primary specialties. The fellowship trains physicians to care for both neurologic and non-neurologic disorders in athletes. Graduates of these sports medicine fellowships can obtain a certificate of added qualifications offered by their primary specialty. Most primary team physicians at the collegiate and professional levels complete this type of fellowship. About three-quarters of primary care sports physicians are based in family medicine. A list of available sports medicine fellowships with procedures for certification appears on the American Medical Society of Sports Medicine website. ${ }^{7}$

There are additional training and certification opportunities for those physicians focused on brain injury. For those in neurology, PM\&R, and psychiatry, there are brain injury fellowships leading to certification through the American Board of Psychiatry and Neurology. ${ }^{8}$ For those trained in neurosurgery, neurotrauma fellowships are available through the Congress of Neurosurgeons; these fellowships tend to focus on major trauma and critical illness. ${ }^{9}$

Practicing neurologists have many options to interact with the world of sports neurology if interested. Many schools, including high schools and colleges, benefit from having neurologists participate in educating their athletes, parents, and coaches about concussion risk and treatment. A physician may choose to make him- or herself available to care for these athletes. In addition, at schools, in athletic clubs, and in the community, patients with neurologic illness may need advice pertinent to a specific area of neurologic specialty regarding their ability to enjoy sports safely (For example: Can a patient with a seizure disorder safely compete in basketball?). Encouraging exercise is important not only for the general health of patients, but also because exercise can improve neurologic outcomes. ${ }^{10}$ Clearly, some of the clinical manifestations of sports concussion and other sports-related neurologic injuries fall in the realm of neurologic subspecialties. For a neurologist in practice who has an interest in concussion, working as a consultant to sports teams from schools, clubs, colleges, or professional organizations can be a rewarding way to support a program and to gain experience as a sports neurology provider. The challenge of this type of practice is that athletes need to be evaluated soon after the event, not only due to return to play considerations, but, most importantly, to make decisions about returning to school or work.

If one were starting out in medical school with a serious interest in sports neurology, what would be the best path? The student would need to assess which of these 2 routes to follow: a neurology residency to a sports neurology fellowship or a primary care residency to a sports medicine fellowship. In medical school, the student should seek out opportunities to work with neurologists who are interested in sports neurology, and learn what types of patients and disorders they see and what types of research they do.

Sports neurology for neurologists breaks down into several job descriptions. There are a small number of sports neurologists who almost exclusively practice sports neurology. They may be tied to an academic environment where they see all sports-related neurologic injuries on campus. They may be part of a major sports medicine/orthopedics practice connected to coverage of groups of teams or work for a private sports neurology company. Some sports neurologists have a practice in pain management, either headache or back pain, as that is a large part of sports neurology and an area that will help support a practice. Many interested neurologists practice 
sports neurology as a portion of their practice while continuing to care for patients with other neurologic disorders. For a physician who wants to center on sports neurology only, a fellowship in sports neurology would be ideal. Sports neurology fellowships include clinical exposure to patients with concussion, peripheral nerve and muscle injuries, vestibular disorders, and neurocognitive issues. Most programs give the fellow time to work assisting teams, usually at the collegiate level. Exposure to procedures such as injections for painrelated complaints is included. Research opportunities are integrated into the fellowship. If a physician wants only a portion of a practice to be related to sports neurology, he or she may consider obtaining other modes of education about sports neurology such as attending conferences dedicated to the topic or shadowing sports neurology providers. Hiring opportunities for specialists in sports neurology from a neurology department perspective may depend on important relationships that need to be cultivated with the department of orthopedics, where the division of sports medicine resides, and with the university athletic department, where the care of undergraduate athletes is organized. The more extensive the integration of the sports neurology practice with these other entities, the more likely a larger amount of time can be spent on specialty care as opposed to other areas in neurology.

During medical school, students should do a rotation with a sports medicine specialist affiliated with the school or working for another athletic organization. If a physician wants to be a team physician, this is the way to go. Team physicians not only care for concussions, but also deal with the athlete's general health, orthopedic injuries, training issues, and diet. One can gain experience covering a sports team or performing preparticipation physicals. The lifestyle that accompanies this type of career may include a lot of travel and difficult hours, and one needs to be exposed beforehand to the pressures of this type of practice.

If choosing a sports medicine rather than sports neurology pathway, a physician would first choose a type of primary care training prior to sports medicine fellowship. One could argue that since many sports medicine physicians will care for both adult and pediatric athletes, primary training in family medicine or a combined medicine/pediatrics residency would be optimal.
Educational opportunities to learn aspects of sports neurology, especially related to concussion, are growing in all medical professional societies. We would recommend that providers who are interested in exploring the subject matter look at the courses offered by the professional society and invite a speaker to their institution or state medical group to address points of interest in sports neurology. Sports neurology is a growing and vibrant specialty with increasing opportunities to participate.

\section{Author contributions}

Dr. Morgenlander: writing of review. Dr. Hainline: critical revision and review of manuscript.

\section{Study funding}

No targeted funding reported.

\section{Disclosure}

J. Morgenlander has received a grant from the Duke Sports Science Institute to study concussion. B. Hainline reports no disclosures relevant to the manuscript. Go to Neurology.org/ $\mathrm{N}$ for full disclosures.

\section{References}

1. Liaison Committee on Medical Education (LCME). Available at: aamc.org/ members/osr/committees/48814/reports_lcme.html. Accessed March 30, 2018.

2. Neurology Clerkship Core Curriculum Guidelines. American Academy of Neurology. Available at: https://www.aan.com/siteassets/home-page/tools-and-resources/ academic-neurologist-researchers/clerkship-and-course-director-resources/neurologyclerkship-core-curriculum-guidelines.new.pdf. Accessed October 2018

3. Accreditation Council for Graduate Medical Education. The Neurology Milestone Project. Available at: acgme.org/Portals/0/PDFs/Milestones/NeurologyMilestones.pdf. Accessed March 30, 2018.

4. Accreditation Council for Graduate Medical Education. The Child Neurology Milestone Project. Available at: acgme.org/Portals/0/PDFs/Milestones/ChildNeurologyMilestones.pdf. Accessed March 30, 2018.

5. Accreditation Council for Graduate Medical Education. Neurological Surgery Milestones. Available at: acgme.org/Portals/0/PDFs/Milestones/NeurologicalSurgeryMilestones.pdf Accessed March 30, 2018.

6. Accreditation Council for Graduate Medical Education. The Physical Medicine and Rehabilitation Milestone Project. Available at: acgme.org/portals/0/pdfs/milestones/pmrmilestones.pdf. Accessed March 30, 2018

7. American Medical Society of Sports Medicine. Available at: amssm.org/Fellowships. html. Accessed March 30, 2018.

8. American Board of Psychiatry and Neurology. Brain Injury Medicine. Available at: abpn.com/ become-certified/taking-a-subspecialty-exam/brain-injury-medicine/. Accessed March 30, 2018

9. AANS/CNS Section on Neurotrauma \& Critical Care. Available at: neurotraumasection.org/education/fellowship.html. Accessed March 30, 2018.

10. Seifert T. Exercise and neurologic disease. Continuum 2014;20:1667-1682.

\section{Are You Ready to Maximize Your Medicare Reimbursement?}

Use the AAN tools and resources to earn positive payments and avoid penalties under MIPS. Take action today, visit AAN.com/view/QPP 


\section{Neurology}

\section{Emerging Subspecialties in Neurology: Sports neurology training and certification: An overview in 2018}

Joel C. Morgenlander and Brian Hainline

Neurology 2018;91;980-982

DOI 10.1212/WNL.0000000000006552

\section{This information is current as of November 19, 2018}

\section{Updated Information \&} Services

References

Subspecialty Collections

Permissions \& Licensing

\section{Reprints}

including high resolution figures, can be found at: http://n.neurology.org/content/91/21/980.full

This article cites 1 articles, 0 of which you can access for free at: http://n.neurology.org/content/91/21/980.full\#ref-list-1

This article, along with others on similar topics, appears in the following collection(s):

All Education

http://n.neurology.org/cgi/collection/all_education Brain trauma

http://n.neurology.org/cgi/collection/brain_trauma

Information about reproducing this article in parts (figures,tables) or in its entirety can be found online at:

http://www.neurology.org/about/about_the_journal\#permissions

Information about ordering reprints can be found online:

http://n.neurology.org/subscribers/advertise

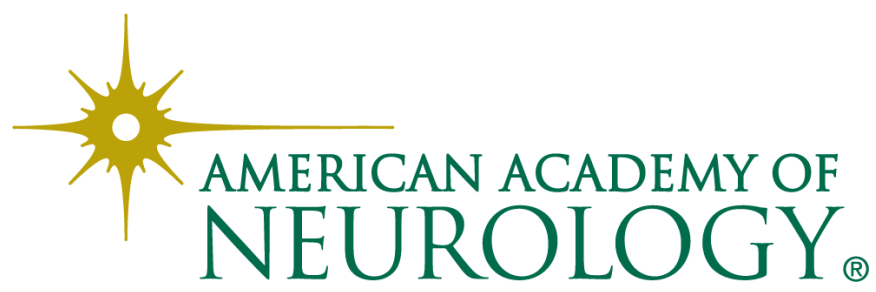

